\title{
GÉNESIS TEÓRICA DEL ESTADO*
}

\section{Jorge Martinez Barrera ${ }^{* *}$}

Tal como señala Alexandre Passerin d'Entrèves, desde la hora de nuestro nacimiento hasta la de nuestra muerte, nuestra vida está marcada por la influencia de varias fuerzas que la dificultan o protegen. Hay fuerzas de tipo natural, pero también hay otras que han sido creadas por nosotros. Entre estas últimas, están las asociadas a una entidad misteriosa pero omnipresente, poseedora de un poder indefinido pero al mismo tiempo irresistible: el Estado1.

El primero en emplear el término 'Estado' en una acepción que es prácticamente idéntica a la contemporánea, fue Maquiavelo en la primera línea de El Príncipe: "Todos los Estados, todos los Dominios que tuvieron y tienen autoridad sobre los hombres, fueron y son repúblicas o principados". Por cierto, sería demasiado pretender exigir a un escritor tan poco sistemático como Maquiavelo una definición precisa del Estado; sin embargo, ya vemos en él un tratamiento del Estado con los caracteres que hoy mismo reconocemos en éste, es decir, como una organización pública dotada de la capacidad de ejercer y controlar el uso de la fuerza sobre una población determinada y en un territorio definido, conforme a un específico cuerpo de derecho soberano.

Pero el término 'estado', no es una invención de Maquiavelo. Ya se lo encuentra en el antiguo derecho romano, aunque con la acepción de 'estado o condición de una cosa', como cuando se dice, por ejemplo, "status rei

" Este trabajo es parte del Proyecto FONDECyT 1050875 (“Génesis teórica del Estado. La significación filosófico- ética de su creación institucional a partir de las polémicas contra la filosofía política clásica"), del cual el autor es Investigador responsable.

** Licenciado en Filosofía por la Universidad Nacional de Cuyo, Argentina (1979). Doctor en Filosofía por la Université Catholique de Louvain, Bélgica (1989). Profesor en la Facultad de Filosofia de la Pontificia Universidad Católica de Chile. Dirección electrónica: jorge_martinez_b2002@yahoo.es

1 Alexandre Passerin d'Entrèves, La notion de l'État. Paris, Sirey, 1969, p. 3. 
publicae". El 'estado', en el derecho romano, designaba también la condición jurídica de una persona o de una comunidad: "status libertatis", "status familiae" o bien "status civitatis". En la Edad Media, 'estado' servía para indicar también una cierta condición social: el 'estado' clerical, el 'estado' de nobleza o el 'estado' popular. De todas estas acepciones, la que probablemente está en el origen del uso contemporáneo es la de "status rei publicae", porque es la que directamente vincula con la comunidad política. Una república, en el sentido romano, no es un Estado, aunque tiene un estado, una condición determinada. Lo que sucede, desde el punto de vista histórico, es que esta república, o en todo caso la comunidad política, tiende a transformarse, mediante los procesos de secularización, en una nueva institución cuya denominación ya no tiene el carácter de transitoriedad o de relativa provisoriedad que existe cuando se habla de "status rei publicae". Ahora se habla sin más del Estado y no del "estado de la cosa pública". En términos filosóficos y con las debidas salvedades, diría que, de accidente que era, el "estado" pasa a transformarse en substancia, de modo que ya no se trata del "estado de la cosa pública", sino de la "cosa pública del Estado". La república es el accidente y el Estado la substancia.

Es muy posible, incluso, que gracias a la difusión extraordinaria del opúsculo de Maquiavelo, este concepto de Estado haya podido alcanzar la significación que hoy tiene en el vocabulario político. Este uso ya es confirmado por Hobbes en la introducción al Leviatán, donde, con una intención explícita, son puestos en un mismo nivel de significación los términos civitas, commonwealth y state. Después de Hobbes, el concepto comienza a ser definitivamente de uso corriente, pues se presta admirablemente bien para designar ese "nuevo principado" que alcanzaba a entrever Maquiavelo. El mismo John Locke, aun cuando no emplea explícitamente el término "Estado" como Hobbes, aclara que se está refiriendo a una realidad política cuyo nombre no interesa, pero que se trata, realmente, de algo novedoso:

Debe quedar bien claro que siempre que empleo la palabra Estado (Commonwealth) no me refiero precisamente a una democracia, ni a ninguna forma concreta de gobierno. Entiendo con esa palabra la comunidad independiente que los latinos llamaban civitas, que es a la que mejor corresponde nuestro vocablo inglés commonwealth. Ésta es la 
que mejor expresa esa clase de sociedad de hombres; mejor que comunidad [porque dentro de un Estado (Commonwealth) puede haber comunidades subordinadas], y mucho mejor todavía que city. Para evitar, pues, ambigüedades, pido permiso para emplear la palabra commonwealth en ese sentido que es el mismo en que ya el rey Jacobo la empleó y que es, a mi entender, el suyo. Si a alguien le desagrada y me sugiere otro más apropiado, estoy dispuesto a admitirlo².

Pero, de cualquier forma que sea, lo cierto es que "el nuevo principado", en el cual "residen la dificultades", según expresión de Maquiavelo, es, con toda verosimilitud, el Estado moderno. Y las dificultades que ve Maquiavelo, son las de cómo concebir una nueva ciencia de la política en la cual ésta aparezca con una autonomía casi completa de la ética, y con un fin casi exclusivamente concentrado en la eficacia de la conservación de esta nueva institución. El capítulo XV de El Príncipe resulta revelador porque allí Maquiavelo recomienda explícitamente el abandono de toda preocupación ética para concentrar sus consejos más bien en la realidad efectiva y cómo sacar provecho de ella para la conservación del "nuevo principado". El texto siguiente sintetiza una idea de incalculables implicancias actuales:

[...] intentando describir cosas útiles para quienes las entienden, me ha parecido preferible ir directamente hacia la verdad efectiva del asunto antes que cuidarme de lo que puede imaginarse sobre él. Muchos concibieron repúblicas y principados jamás vistos y que nunca existieron. Es que hay tanto trecho de cómo se vive a cómo debería

${ }^{2}$ John Locke, Segundo tratado del gobierno civil, par. 133, traducción de Amando Lázaro Ros, Madrid, Editorial Aguilar, 1973. Alexandre Passerin d'Entrèves señala ( $o p$. cit., p. 43) que en el mundo anglófono, especialmente en Inglaterra y Estados Unidos, el término 'estado' no ha tenido la aceptación generalizada que tuvo en los países latinos. En Inglaterra, por ejemplo, hubo necesidad de una ley en 1887 para explicar que frases tales como "Servicio de la Corona", "Servicio de Su Majestad" y "Servicio del Estado", tienen la misma significación. La razón de esta resistencia, dice Passerin d'Entrèves, podría encontrarse en la profunda desconfianza de estas culturas hacia los conceptos demasiado abstractos. Pero lo cierto es que las circunlocuciones que se emplean para evitar el término 'Estado', indican, sin embargo, la misma realidad estatal. 
vivirse, que quien renuncia a lo que se hace por lo que se debería hacer, aprende más bien lo que le arruinará que lo que le preservará. El hombre que quiera hacer profesión de bueno, cuando le rodean tantos malos, correrá a su perdición.

El elogio de Francis Bacon a Maquiavelo va al nudo del asunto cuando escribía en 1605 que "tenemos una gran deuda respecto de Maquiavelo y algunos otros que han descrito lo que los hombres hacen y no lo que deberían hacer, porque no es posible unir la duplicidad de la serpiente a la inocencia de la paloma si no se conocen exactamente todos los recursos de aquélla: su abyecta bajeza, su pérfida agilidad, el odio que agudiza su dardo"3.

En ese sentido, Maquiavelo no solamente fue un producto de su época, sino también, tal vez, el mejor intérprete de la misma, además de ser el creador oficial, de manera indirecta, del concepto de "Razón de Estado", según la cual, los actos destinados a la conservación de éste no son pasibles de dictamen judicial, y mucho menos, ético ${ }^{4}$.

Después de Maquiavelo, la ciencia política ha tendido a evitar cuidadosamente expresarse como ciencia normativa. La preocupación esencial del politólogo contemporáneo no es de orden ético-formativo, sino analítico-descriptivo, y deja a los hombres de Estado o a los políticos la responsabilidad de extraer las conclusiones prácticas del universo de datos que le son proporcionados a la manera de un sistema. El problema político se vuelve casi un problema técnico. El siguiente texto de Kant es muy elocuente al respecto:

La constitución republicana (republikanische Verfassung), la única que es plenamente conforme a los derechos del hombre, es también la más difícil de establecer y más difícil aún de conservar. Por eso muchos pretenden que ella sólo es posible en un pueblo de ángeles porque los hombres, con sus inclinaciones egoístas, son incapaces de una forma de

${ }^{3} \mathrm{~F}$. Bacon, On the Proficience and Advancement of Learning divine and buman (II, xxi, 9).

${ }^{4}$ Es ya un clásico el trabajo de F. Meinecke, La idea de razón de Estado en la edad moderna, traducción de Felipe González Vicén, Madrid, Centro de Estudios Constitucionales, 1997. 
gobierno tan sublime. Pero la naturaleza se sirve precisamente de esas inclinaciones interesadas para venir en socorro de la voluntad general, la cual se funda en la razón, pero que, por respetada que sea, resulta impotente en la práctica. De manera que basta para la buena organización del Estado (cosa que ciertamente está al alcance del hombre) con enfrentar unas contra otras las fuerzas de esas inclinaciones para que una neutralice los efectos desastrosos de las otras o los aniquile. De este modo, desde un punto de vista racional, resulta que todo sucede como si esas dos tendencias no existieran y el hombre se viera obligado a ser, si no moralmente bueno, por lo menos un buen ciudadano. El problema de la constitución de un Estado puede incluso ser resuelto para un pueblo de demonios, por extraño que esto pueda parecer (si éstos tienen, por lo menos, entendimiento), y he aquí cómo tal problema se plantea: 'ordenar de tal forma una multitud de seres racionales, los cuales desean para su conservación leyes generales, pero de las que están dispuestos, secretamente, a exceptuarse a sí mismos, y darles una constitución tal que, a pesar del antagonismo producido por sus inclinaciones personales, éstas se obstaculicen mutuamente de tal manera, que en la vida pública de esas personas su comportamiento sea el mismo que si esas inclinaciones no existieran'. Semejante problema debe poder ser resuelto. El asunto, pues, no es el de saber cómo se puede mejorar moralmente a los hombres, sino cómo podemos servirnos del mecanismo de la naturaleza para dirigir de tal forma el antagonismo de sus disposiciones hostiles, de tal modo que todos los individuos de un mismo pueblo se obliguen entre sí a someterse a leyes coercitivas y establezcan en consecuencia un estado de paz donde las leyes estén en vigor ${ }^{5}$.

Por cierto, cuando hablamos del Estado nos enfrentamos con una situación paradójica. Por una parte sería un desvarío negar su existencia institucional, pero por otra parte enfrentamos enormes dificultades a la hora de circunscribir su esencia, de definirlo, o por lo menos, de describirlo con alguna precisión. Pero una cosa salta a la vista. El Estado, si lo consideramos como una cuestión de hecho, se nos presenta fundamentalmente como una

${ }^{5}$ Immanuel Kant. Un ensayo filosófico sobre la paz perpetua (1795). Primer suplemento: "Sobre la garantía de la paz perpetua", N 1 . 
institución que monopoliza la fuerz $d^{6}$. Una de sus caras más visibles, la que está tal vez más en contacto con los ciudadanos, por ejemplo, es la policia, en cualquiera de sus expresiones?

Pero además de esto, hay también otro factor que es esencial al Estado: si bien se trata de una institución monopolizadora de la fuerza, ésta no puede o no debe jamás ser arbitraria, sino sometida a ciertas normas, pero cuya instancia de legitimación, y esto es muy importante, es el Estado mismo. En este sentido, Max Weber ha dado una definición del Estado que sintetiza claramente su esencia:

El Estado moderno es una asociación de dominación con carácter institucional que ha tratado, con éxito, de monopolizar dentro de un territorio la violencia física legítima como medio de dominación y que, a este fin, ha reunido todos los medios materiales en manos de su dirigente $\mathrm{y}$ ha expropiado a todos los funcionarios estamentales que antes disponían de ellos por derecho propio, sustituyéndolos por sus propias jerarquías supremas ${ }^{8}$.

El Estado es siempre un Estado de derecho, un cuerpo jurídico. Éste es consubstancial al Estado, incluso en los casos en que se trate de formas patológicas del mismo. El Estado fascista, por ejemplo, no se opone tan radicalmente como puede suponerse a la estructura general de la institución

${ }^{6}$ Escribe Maquiavelo en El principe, cap. XII: "Los cimientos de todos los Estados, recientes, antiguos o mixtos, son las leyes justas y las armas fuertes. Como no puede haber leyes buenas donde no son buenas las armas, y donde hay buenas armas conviene que las leyes sean buenas, prescindiré de éstas y hablaré de aquéllas." No puede haber leyes buenas si no hay buenas armas. La "bondad" de la ley es así la misma que la de las armas.

${ }^{7} \mathrm{Ha}$ sido últimamente Michel Foucault quien ha llamado la atención acerca de la importancia de la institución policial en el afianzamiento del Estado. Las alusiones a este asunto se encuentran en varias de sus obras, pero un buen tratamiento del mismo puede verse, por ejemplo, en Michel Foucault, "Omnes et singulatim: hacia una crítica de la razón política", en Tecnologias del yo y otros textos afines, introducción de Miguel Morey, Barcelona, Ediciones Paidós Ibérica, 1996, pp. 122 y ss.

8 Max Weber. "La política como profesión", conferencia pronunciada en 1919 y recogida en El politico y el cientifico, traducción de Francisco Rubio Llorente, Madrid, Alianza Editorial, 1986, p. 92. 
estatal. También el Estado fascista es, a su manera, un Estado de Derecho en la medida en que su funcionamiento depende del monopolio de la fuerza y de un cuerpo jurídico específico de él ${ }^{9}$. Esto lleva a una tercera característica del Estado: es una institución soberana. De hecho, el concepto de soberania nace con el Estado ${ }^{10}$. Pero una cosa debe quedar expuesta con la suficiente claridad: todo lo que el Estado es, puede siempre, de una u otra manera, referirse al ámbito del derecho y la ley. El Estado es una institución jurídica y todas sus acciones están mediatizadas por su novedosa comprensión del derecho. De ahí la urgencia, vivamente sentida por el padre fundador del Estado, Thomas Hobbes, de una redefinición de la semántica jurídica.

Sin embargo, aun cuando es cierto que la aparición y consolidación del Estado es un fenómeno exclusivamente moderno que puede situarse en los comienzos del siglo XVI en algunas ciudades italianas, la idea de que la comunidad política es una comunidad en la cual las relaciones intersubjetivas tienen que estar reguladas por una ley, no es nueva, no es una creación del Estado moderno ${ }^{11}$. Ya se la encuentra formulada en los autores

${ }^{9}$ Ésta fue una de las grandes cuestiones que se planteó en el juicio de Nüremberg: el Estado nazi, ¿es verdaderamente un Estado? Es también el problema planteado por San Agustín en La ciudad de Dios: el Imperio romano, ¿es realmente una comunidad política?

${ }^{10}$ Las principales características del Estado están resumidas por Thomas Hobbes en el cap. XVII del Leviatán: a) contrato, b) monopolio de la violencia física, c) representación y d) soberanía.

11 Un antecedente medieval muy importante del Estado fue el Reino de Sicilia, bajo el Emperador Federico II Hohenstaufen (Barbarroja) (1112-1250). Este fue uno de los primeros Estados administrativos. Pero no hay que olvidar otros antecedentes importantes, como la Inglaterra de Enrique II Plantagenet (1154-1189), la Francia de San Luis (1226-1270), y la Castilla de Fernando el Santo (1217-1252) y de su sucesor Alfonso el Sabio (1152-1258). Ver Freiherr von der Heydte, Die Geburtsstunde des souveränen Staates, p. 41, citado por J. P. Galvao de Sousa, O totalitarismo nas origens da moderna teoria do Estado. Sao Paulo, 1972, p. 61. No debemos olvidar tampoco el importantísimo antecedente tardomedieval del pensamiento de Marsilio de Padua con su Defensor Pacis (1324), para justificar la posición de Luis II de Baviera contra el Papa Juan XXII. Un estudioso como Georges de Lagarde no duda en llamar a Marsilio "el primer teórico del estado laico" (ver Georges de 
clásicos. Pero, a pesar de esto, es innegable que el concepto de 'Estado' no figura en el vocabulario político premoderno, ni en el medieval y mucho menos en el clásico.

Es muy interesante comprobar los esfuerzos realizados por los escritores políticos de la Baja Edad Media por captar la esencia de una nueva realidad política que comenzaba ya a tomar forma delante de sus ojos. Y el esbozo histórico de esta nueva realidad política es coincidente con la introducción de la Política de Aristóteles en el Occidente latino. Hay allí, en la Politica, una idea que se prestaba admirablemente bien para lo que empezaba a tomar forma. En efecto, para Aristóteles la pólis, la ciudad, es, no solamente la última instancia en la perfección de las diferentes posibilidades asociativas humanas, sino, sobre todo, una communitas perfecta et sibi sufficiens, o sea, algo que se aproxima mucho a la noción moderna del Estado. Obviamente, existe un interés de leer a Aristóteles de manera bastante sesgada, pues no se podría afirmar que la misma comunidad política es para el Estagirita la fuente última de convalidación del sistema normativo. En efecto, si la ciudad es la comunidad perfecta y autosuficiente, ¿cuál es el papel de la Iglesia en todo esto? Las virulentas disputas entre Papas y Emperadores son la evidencia de que la nueva realidad política ya no ve con simpatía la injerencia eclesiástica en materias mundanas, esencialmente ético-políticas. En este sentido, se pueden comprobar dos tipos de estrategias argumentativas contra la intrusión eclesiástica en asuntos ético-políticos. Una, la de Maquiavelo, consiste en decir: "este hombre (en este caso, el Papa) es un inmoral, por lo tanto, lo que él diga sobre estos asuntos está descalificado por su propia conducta". Veamos el siguiente texto de los Discorsi:

Muchos opinan que el bienestar de las ciudades de Italia se debe a la Iglesia romana, a lo que replico con algunas razones, entre ellas, dos muy poderosas, que, en mi parecer, no tienen objeción. Es la primera que, contemplando los malos ejemplos de aquella corte, este país ha perdido toda devoción y religión. Ello genera infinitos inconvenientes y mil desórdenes, porque así como hay que presuponer el bien en donde

Lagarde, La naissance de l'esprit lä̈que au déclin du Moyen Âge, Vol. II, Louvain-Paris, 1956-1958). 
reina la religión, así hay que suponer lo contrario en los lugares en que falta. Los italianos hemos de agradecer a los representantes de la Iglesia el estar perdidos y sin fe. Pero aún se cuenta otro motivo mayor de nuestra ruina, y es mi segunda razón: la Iglesia ha tenido y tiene a Italia dividida [...]. La causa de que Italia no se halle en igual situación [que Francia y España], ni tenga una república o un príncipe que la gobierne, no es más que la Iglesia. Después de habitar en ella y de gozar de poder temporal, no tuvo fuerza ni valor para ocupar el resto de Italia, a modo de principado; pero tampoco, en un aspecto contrario, ha sido tan débil que, medrosa de perder su autoridad en las cosas temporales, pidieron auxilio a un poderoso que la protegiese de una exagerada potencia italiana [...]. La Iglesia no tuvo, por tanto, fuerza para dominar a Italia, ni consintió que otro la ocupase [...]. Para tener experiencia pronta de esa verdad, convendría que un potente señor enviase la corte romana, con la autoridad que ahora posee en Italia, a habitar en tierras de los suizos, único pueblo que hoy vive como los antiguos en lo referente a la religión y a las costumbres militares. Veríase como en poco tiempo, mucho antes que cualquier acaso que pudiera surgir, desordenarían aquella nación las malas costumbres de esa corte ${ }^{12}$.

La estrategia argumental de Hobbes, en cambio, va directamente al núcleo dogmático y puede resumirse así: "los dogmas católicos no pueden ser científicamente demostrados, por lo tanto, todo cuanto diga la Iglesia no es más que una fantasía destinada a someter las conciencias". Hay en Hobbes un propósito manifiesto de romper con la tradición, y de manera especial con todo cuanto tenga que ver con la Iglesia de Roma. Recordemos que se trata, para Hobbes, de refundar el derecho, excesivamente configurado, para su gusto, por su dependencia de un sistema de moralidad cuyo representante más visible es el pensamiento de la Iglesia de Roma. Ésta habría producido un intolerable engendro llamado "escolástica", del cual Aristóteles sería la eminencia gris. Estos ataques alcanzan una particular virulencia en el Leviatán. Veamos, a modo de ejemplos, algunos pasajes donde el filósofo no ahorra diatribas contra la Iglesia y todo cuanto a su

12 Discursos sobre la primera década de Tito Livio (1513-1519), en: Maquiavelo, Obras, versión, prólogo y notas de Juan A. G. Larraya. Barcelona, Editorial Vergara, 1965. Libro I, cap. XII. Existe una nueva edición en español de los Discorsi: Discursos sobre la primera década de Tito Livio, estudio preliminar, traducción y notas de Roberto Raschella, Buenos Aires, Editorial Losada, 2003. 
juicio la sustenta. Desde la filosofía aristotélica hasta la teología sacramental, no debe quedar nada en pie: "[...] creo que pocas cosas pueden decirse más absurdamente en filosofía natural que lo actualmente llamado metafisica aristotélica, ni cosa más repugnante al gobierno que lo dicho por Aristóteles en su Politica, ni más ignorantemente que una gran parte de sus Éticas" (Cap. $\mathrm{XLVI}$ ).

\section{Cap. XLVII:}

En primer lugar [pretendo examinar] el error de que la actual Iglesia boy militante sobre la tierra es el reino de Dios [...]. A este error se adhieren los siguientes beneficios terrenales; en primer lugar, que los pastores y profesores de la escuela poseen, como ministros públicos de Dios, un derecho a gobernar la Iglesia y, en consecuencia (puesto que la Iglesia y la república son la misma persona), a ser rectores y gobernantes de la república. Mediante este título prevaleció el Papa sobre los súbditos de todos los príncipes cristianos a la hora de hacer creer que desobedecerle era desobedecer al propio Cristo; y consiguió hacer que en todas las diferencias entre él y otros príncipes (embrujados con la palabra poder espiritual) el pueblo abandonase a sus legítimos soberanos, lo cual constituye en efecto una monarquía universal sobre toda la cristiandad [...]. Desde que el obispo de Roma logró ser reconocido como obispo universal pretendiendo suceder a San Pedro, toda su jerarquía o reino de tinieblas puede compararse sin violencia al reino de las hadas, esto es, a las fábulas de las viejas en Inglaterra sobre fantasmas y espiritus y los actos que realizan en la noche. Y si un hombre considera el origen de este gran dominio eclesiástico percibirá fácilmente que el papado no es sino el fantasma del fallecido Imperio romano, que se sienta coronado sobre su tumba. Porque así brotó súbitamente el papado de las ruinas de ese poder pagano [...]. Las ancianas no han determinado en qué tienda o lugar hacen las hadas sus encantamientos. Pero los lugares del clero sabemos sobradamente que son las universidades, cuya disciplina proviene de la autoridad pontificia.

\section{Cap. XLIV:}

[No es más que un conjuro y un encantamiento] cuando el sacerdote pretende que diciendo las palabras de nuestro Salvador este es mi cuerpo y esta es mi sangre la naturaleza del pan ya no está allí y se trata de su cuerpo mismo, cuando allí no aparece ni para la visión ni para ningún otro sentido del receptor cosa alguna que no estuviese presente antes de la 
consagración. Los magos egipcios, de los que se dice que convertían sus varas en serpientes y el agua en sangre, debieron haber engañado los sentidos de los espectadores mediante una falsa exhibición de cosas, y sólo así consiguieron ser considerados encantadores. Sin embargo, ¿qué habríamos pensado de ellos si en sus varas no hubiese aparecido nada semejante a una serpiente y en el agua encantada no hubiese aparecido nada semejante a la sangre, ni cosa distinta del agua misma, y volviendo sus rostros al rey dijesen que se trataba de serpientes con aspecto de bastones y de sangre con aspecto de agua? Habríamos pensado que allí había encantamiento tanto como embuste. Con todo, los sacerdotes hacen en sus actos diarios eso mismo, transformando las palabras sagradas en un encantamiento que nada nuevo produce para el sentido. Pero ellos mantienen que han convertido el pan en un hombre o, más aún, en un Dios, y exigen de los hombres que lo adoren, como si sc tratase de nuestro Salvador mismo, en su forma de Dios y de hombre, cometiendo así la más grosera de las idolatrías [...]. Las palabras este es mi cuerpo son equivalentes a esto significa o representa mi cuerpo, y constituyen una figura común del lenguaje. Pero tomarlas literalmente es un abuso. $\mathrm{Y}$ aunque se tomen así, en ningún caso pueden extenderse más allá del pan que el propio Cristo consagró con sus propias manos. Porque él nunca dijo que ningún pan del cual algún sacerdote dijera este es mi cuerpo o este es el cuerpo de Cristo se transubstanciaría efectivamente.

\section{Cap. XII:}

[...] la semilla natural de la religión consiste en estas cuatro cosas: creencia en fantasmas, ignorancia de causas segundas, devoción hacia lo temido por los hombres y asunción de cosas casuales como pronósticos [...]. Esas semillas han sido cultivadas por dos tipos de hombres. Unos las han alimentado y ordenado con arreglo a su propia invención. Otros lo han hecho por mandamiento y dirección de Dios. Pero ambos lo hicieron con el propósito de volver a sus fieles más aptos para la obediencia, las leyes, la paz, la caridad y la sociedad civil. [...] ¿Será alguien incapaz de ver a quién beneficia creer que un rey no recibe su autoridad de Cristo si no le corona un obispo? [...] ¿Que los súbditos puedan quedar desvinculados de su juramento de obediencia si el tribunal de Roma considera herético al rey? ¿Qué un rey (como Chilperico de Francia) pueda ser depuesto sin causa por un Papa (como el Papa Zacarías) y entregarse su reino a uno de sus súbditos? [...] ¿O acaso no ve cualquiera a quién benefician los precios de las misas 
privadas y los vales de purgatorio, junto con otros signos de interés privado suficientes para mortificar la más viva fe si no los sostuvieran la magistratura civil y la costumbre antes que la opinión sobre la santidad, la sabiduría o la probidad de sus maestros? Por lo mismo, puedo atribuir todos los cambios de la religión en el mundo a una sola causa: sacerdotes que no complacen.

Resulta también curioso que en los casos cuando esas disputas alcanzaron sus puntos más altos, el argumento de los emperadores o reyes contra la supremacía espiritual del Papa solía asentarse en críticas a la conducta personal de los Papas antes que en argumentos racionales acerca de por qué no era admisible la jurisdicción de la Iglesia en asuntos mundanos. Era como si los Emperadores dijesen, con Maquiavelo, "no podemos aceptar la jurisdicción en materias morales de una institución cuyos mismos miembros están corrompidos".

En la lucha contra la institución eclesiástica, o lo que es lo mismo decir, en el proceso de afianzamiento del espíritu secular, Aristóteles fue de un gran auxilio, pero es preciso advertir que la lectura de éste fue hecha de manera bastante sesgada, como dije más arriba. Esto se ve en lo siguiente.

Para Aristóteles, si bien es cierto que la pólis perfecta es autosuficiente en materia ético-política, no podría decirse sin embargo que ella sea autónoma, en el sentido de que ella es, sin más, el referente último de convalidación de orden normativo ético-político. Autosuficiencia no es autonomía. Es evidente que en el pensamiento aristotélico, a favor de una antigua y venerable tradición, todo lo referido al orden de la justicia en la ciudad está abierto a una legitimación extrapolítica ${ }^{13}$. Por eso, si bien en Aristóteles, e incluso en Platón, ya tenemos un serio precedente de la idea de que la vida política requiere formas de regulación jurídica, hay un mundo de diferencia respecto de lo que estos autores entienden por ley y lo que la moderna teoría del Estado entiende.

${ }_{13}$ Aristóteles no podía ignorar el mito de Prometeo, ya relatado por Esquilo y coincidente, casi de manera total, con el relato de Platón en el Protágoras, 320d - 322 d. Ver Werner Jaeger, Alabanza de la ley. Los origenes de la filosofia del derecho y los griegos, traducción de A. Truyol y Sierra, Madrid, Centro de Estudios Constitucionales, 1982, pp. 40 y ss. 
A pesar de todo, no puede dudarse de que con Cicerón hay un cambio de matiz respecto de Aristóteles. En efecto, para el Estagirita, si bien es cierto que el asunto de la ley ocupa un puesto privilegiado en su pensamiento político, su interés primordial respecto de las cosas políticas sigue siendo el de la eupraxía, el de la acción buena y el de la buena sociedad, objetivo al cual se subordina el asunto de la legislación ${ }^{14}$. Para Cicerón, en cambio, e insisto en que se trata todavía de un matiz y no de una diferencia sustancial, ese interés se desplaza hacia la legislación, digamos, a la estructura jurídica que ofrece una especie de plan general de convivencia ${ }^{15}$. A Cicerón

14 "La ley ordena hacer lo que es propio del valiente, por ejemplo, no abandonar la formación, ni huir ni arrojar las armas; y lo que es propio del hombre morigerado, como no cometer adulterio, ni comportarse con insolencia; y lo que es propio del hombre de carácter apacible, como no dar golpes, ni hablar mal de otros; e igualmente lo que es propio de las demás virtudes y formas de maldad, mandando lo uno y prohibiendo lo otro, rectamente cuando la ley está bien establecida y peor cuando ha sido establecida arbitrariamente" (Ética Nicomaquea $1129 \mathrm{~b} 19$ y ss). "[...] por lo general, la mayoría de las disposiciones legales están constituidas por prescripciones de la virtud total, porque la ley manda vivir de acuerdo con todas las virtudes y prohíbe que se viva en conformidad con todos los vicios. $Y$ de las disposiciones legales, sirven para producir la virtud total todas aquellas establecidas acerca de la educación para la vida en comunidad" (Ibid., 1130b 22 y ss).

${ }^{15}$ No podemos obviar el hecho de que para Aristóteles, de alguna forma contra el Platón de República, la primacía en la autoridad de la comunidad política debe ser de la ley antes que de los hombres: "[...] es preferible que la ley gobierne antes que uno cualquiera de los ciudadanos [...]. Se dirá, sin duda, que las cuestiones que la ley parece no poder decidir tampoco podría conocerlas un hombre. Pero la ley educa expresamente a los gobernantes y prescribe que éstos juzguen y administren con el criterio más justo lo que cae fuera de su alcance. Es más, concede la facultad de rectificarla cuando la experiencia sugiera alguna mejora de sus disposiciones. Por tanto, el que defiende el gobierno de la ley defiende el gobierno exclusivo de la divinidad y la razón y el que defiende el gobierno de un hombre añade un elemento animal, pues no otra cosa es el apetito, y la pasión pervierte a los gobernantes y a los mejores de los hombres. La ley es, por consiguiente, razón sin apetito" (Politica, 1287a 19-32). "Además, las leyes consuetudinarias (bói katá éthe nómoi) son más importantes y versan sobre cosas más importantes que las escritas" (Ibid., 1287b 58). "Donde las leyes no tienen supremacia surgen los demagogos" (Ibid., 1292a 10). "[...] donde las leyes no tienen autoridad no hay república. La ley debe estar por encima de todo, y los magistrados y la república deben decidir únicamente de los 
debemos la idea de la importancia capital del derecho en la organización de la convivencia política, aunque por cierto, si nos atenemos a su concepto de ley, está claro que sería muy difícil acusarlo de "juridicista" en el sentido en que hoy hablamos de ese término ${ }^{16}$. La ley, para Cicerón, tiene una conexión esencial con el sistema de la moralidad:

Si los derechos se fundaran en la voluntad de los pueblos, las decisiones de los príncipes y las sentencias de los jueces, sería jurídico el robo, jurídica la falsificación, jurídica la suplantación de los testamentos, siempre que tuvieran a su favor los votos o los plácemes de una masa popular. Y si el poder de la opinión y voluntad de los estúpidos es tal que pueden éstos, con sus votos, pervertir la naturaleza de las cosas, ¿por qué no sancionan que se tenga por bueno y saludable lo que es malo y pernicioso? Y, ¿por qué, si la ley puede convertir en algo justo la injusticia, no puede también convertir en bueno lo malo? Y es que para distinguir la ley buena de la mala no tenemos más norma que la de la naturaleza [...]. La naturaleza nos dio así un sentido común, que esbozó en nuestro espíritu, para que identifiquemos lo honesto con la virtud y

casos particulares. De modo que si la democracia es una de las formas de gobierno, una organización tal que en ella todo se hace por medio de decretos no es tampoco una verdadera democracia [...]" (Ibid., 1292a 32-37).

16 'Es, pues -dijo Africano-, la 'república' la 'cosa del pueblo', y el pueblo, no toda agrupación de hombres congregada de cualquier manera, sino la agrupación de una multitud, asociada por un consenso de derecho (iuris consensu) y la comunidad de intereses. Y su primer motivo de agruparse es no tanto la debilidad como, por así decir, la propensión natural de los hombres a congregarse" (Cicerón, De la repuiblica, I, XXV, 39). "La verdadera ley es la recta razón congruente con la naturaleza, difundida en todos, constante, sempiterna, la cual, ordenando, llama al deber; vedando, aparta del fraude [...]. Ni está permitido que esta ley sea anulada por otra, ni es lícito que se derogue alguna parte de ella, ni puede ser abrogada toda ella, y tampoco podemos ser desatados de esta ley por medio del senado o por medio del pueblo; ni debe buscarse otro comentador o intérprete de ella, ni habrá una ley en Roma, otra en Atenas, una ahora, otra después, sino que una sola ley, tanto sempiterna como inmutable, contendrá a todas las naciones y en todo tiempo, y Dios será el único, por así decir, maestro común y gobernante de todos: aquel autor, argumentador y promulgador de esta ley" (Ibid., III, XXII, 33). 
lo deshonesto con el vicio. Pensar que eso depende de la opinión de cada uno y no de la naturaleza, es cosa de locos (dementis est $)^{17}$.

La primacía del derecho es un tema recurrente en el pensamiento político medieval, aun cuando es cierto que se la asocia con una legalidad de un tipo muy diferente a la del Estado moderno. Las concepciones políticas medievales, incluso de manera especial la del mismo Santo Tomás de Aquino, ofrece un amplio lugar al derecho, como lo prueban las permanentes citas de los juristas romanos. Santo Tomás, al igual que sus predecesores, enfatiza la sustancial vinculación entre ética y derecho ${ }^{18}$.

${ }^{17}$ Cicerón, De legibus, I, 16.

18 "La ley es una regla y medida de nuestros actos según la cual uno es inducido a obrar o dejar de obrar. Ahora bien, la regla y medida de nuestros actos es la razón que, como ya vimos, constituye el primer principio de los actos humanos, puesto que propio de la razón es ordenar al fin" (Summa Theologiae, Ia-IIae, q.90, a.1 c.). "[...] como el último fin de la vida humana, según ya vimos, es la felicidad o bienaventuranza, síguese que la ley debe ocuparse primariamente del orden a la bienaventuranza. Además, la parte se ordena al todo como lo imperfecto a lo perfecto, y el hombre individual es parte de la comunidad perfecta. Luego es necesario que la ley se ocupe de suyo del orden a la felicidad común [...]. Como la ley se constituye primariamente por el orden al bien común, cualquier otro precepto sobre actos particulares no tiene razón de ley sino en cuanto se ordena al bien común. Se concluye, pues, que toda ley se ordena al bien común" (Ibid., a.2 c.). "El efecto propio de la ley es hacer buenos a sus destinatarios, bien en un sentido absoluto, bien en un sentido relativo. Porque si el legislador se propone conseguir el verdadero bien, que es el bien común regulado en consonancia con la justicia divina, la ley hará buenos a los hombres en sentido absoluto. Si, en cambio, lo que el legislador se propone no es el bien verdadero, sino un bien útil o deleitable para él mismo, o no acorde con la justicia divina, entonces la ley no hace buenos a los hombres en sentido absoluto, sino sólo en sentido relativo, es decir, bueno para un determinado régimen" (Ibid., q. 92, a.1 c.). "En consecuencia, es imposible alcanzar el bien común de la comunidad si los ciudadanos no son virtuosos, al menos los gobernantes; porque en cuanto a los otros, basta para lograr el bien común que sean virtuosos en lo tocante a obedecer a quien gobierna" (Ibid., Ad 3m). "No hay, por lo tanto, virtud alguna cuyos actos no puedan ser prescritos por la ley. Salvo que la ley humana no se ocupa de todos los actos de todas las virtudes, sino sólo de aquellos que se refieren al bien común, ya sea de manera inmediata, como cuando se presta directamente algún servicio a la comunidad, ya sea de manera mediata, como 
También en este caso y a la manera del estoicismo ciceroniano, la innegable importancia del derecho y lo jurídico en la estructuración del pensamiento político va de la mano de una paralela insistencia en la noción de ley natural, hasta tal punto que ésta, cuyo origen último divino está sin embargo mediatizado por el intelecto humano, es el definitivo garante de la legitimidad del mismo orden jurídico. Incluso más, Santo Tomás parece haber sido el primero en dar un empleo sistemático a una nueva noción de ley: la lex aeterna, entendida como la razón de Dios en su función gobernadora. Ésta es, en su pensamiento, la ley suprema y absoluta de la cual dependen todos los sistemas legales particulares. De todos modos, la idea de hacer coincidir prácticamente la existencia de una comunidad política con un sistema jurídico, en cierta medida ya está instalada. Toda la diferencia radica en qué haya de entenderse por ley y derecho. De esto es perfectamente consciente Thomas Hobbes. Mientras no se produzca la desvinculación conceptual de ley y derecho de sus referentes "metafísicos", la reformulación del vocabulario jurídico, esencial para el afianzamiento teórico del Estado, no será posible ${ }^{19}$.

Ahora bien, en el Derecho Romano existía una célebre norma con una frondosa historia por detrás, que decía: "quod omnes tangit ab omnibus

cuando el legislador adopta medidas para dar a los ciudadanos una buena educación que les ayude a conservar el bien común de la justicia y de la paz" (Ibid., q.96, a.3 c.). 19 "El DERECHO NATURAL, que los escritores llaman comúnmente jus naturale, es la libertad que cada hombre tiene de usar su propio poder, como él quiera, para la preservación de su propia naturaleza, es decir, de su propia vida y, por consiguiente, de hacer toda cosa que en su propio juicio y razón conciba como el medio más apto para aquello. Por LIBERTAD se entiende, de acuerdo con la significación apropiada de la palabra, la ausencia de impedimentos externos, impedimentos que a menudo pueden arrebatar a un hombre parte de su poder para hacer lo que le plazca [...].Una LEY DE NATURALEZA (lex naturalis) es un precepto o regla general encontrada por la razón, por la cual se le prohíbe al hombre hacer aquello que sea destructivo para su vida, o que le arrebate los medios de preservar la misma, y omitir aquello con lo que cree puede mejor preservarla, pues aunque los que hablan de este tema confunden a menudo jus y lex, derecho y ley, éstos debieran, sin embargo, distinguirse, porque el derecho consiste en la libertad de hacer o no hacer, mientras que la ley determina y ata a uno de los dos, con lo que la ley y el derecho difieren tanto como la obligación y la libertad, que en una y la misma materia son incompatibles" (Thomas Hobbes, Leviathan, cap. XIV). 
approbetur", esto es, lo que concierne a todos, por todos debe ser aprobado. Bastará un ligero desplazamiento respecto del origen último de convalidación de un sistema jurídico, para que haga su aparición una nueva teoría que caracterizará, junto con el aparato legal, al estado moderno: la soberania.

La soberanía no es el equivalente exacto de la "Summa potestas" o de la "majestas" del poder político, pues estas nociones remiten por lo general a una fundamentación trascendente del orden jurídico-normativo. Pero si esa legitimación cede su lugar a la clausura del sistema jurídico sobre sí mismo, de manera de hacer de él una totalidad autonormativa y autolegitimante, se obtiene con ello uno de los rasgos esenciales que dará sustento al Estado. En efecto, puesto que éste se expresa, ante todo, como sistema jurídico, cuando ese sistema interrumpa su comunicación o participación en un sistema de legalidad jerárquicamente superior, tal como el que ofrecía la teoría de la ley natural, el Estado mismo es la consecuencia directa de esa autojustificación. Dicho de otro modo, cuando el sistema jurídico se vuelve autosuficiente respecto de su propia convalidación, ése es el momento teórico del nacimiento del Estado. Sería pues, extremadamente complicado articular la esencia del Estado sobre una ley que no se reconociera a sí misma, de hecho y en el uso práctico, como instancia suprema de legitimidad, aun cuando de derecho o en lo puramente teórico los sistemas normativos estatales declamen su dependencia y respeto por la razón divina.

Es perfectamente comprensible que el primer titular histórico de la soberanía deba ser un monarca. Pero lo que aquí importa no es el titular de la soberanía, pues éste cambiará con el correr del tiempo; lo verdaderamente significativo en este asunto es que el sistema legal que da sustento a la comunidad política ya no necesita referirse a un nivel extrajurídico para justificarse. $\mathrm{Y}$ es este sistema legal el que está indisolublemente ligado al nacimiento del Estado.

El primer teórico en emplear de manera explícita y sistemática la expresión "poder soberano" es Jean Bodin en sus Seis Libros sobre la República (1576). Esto él lo sabe y reivindica su descubrimiento de la soberanía. Su definición de República introduce el concepto que ya no será abandonado por el Estado: "República es el recto gobierno de varias familias y de cuanto les 
es común, con poder soberano (République est un droit gouvernement de plusieurs mesnages et de ce qui leur est commun, avec puissance souveraine)".

Esta definición tuvo una fortuna inmensa en la génesis intelectual del Estado. Según Bodin, lo que distingue al Estado (en este caso él lo llama "República") de cualquier otra clase de asociación, es nada menos que la soberanía. Un Estado, por pequeño que sea, seguirá siendo tal mientras sea soberano. A su vez, el ciudadano es un hombre libre, pero al mismo tiempo igual, en términos casi absolutos, a todos los demás sujetos de la soberanía. Cualesquiera sean las diferencias en rango social, la soberanía iguala a todos los que le están sometidos. Frente a ella, el ciudadano se despoja de su condición de amo, de jefe o de señor, dice Bodin, y depende de una regla general que es la misma para todos. Cuando Bodin habla de recto gobierno, se refiere, sí, a un gobierno moral, pero esa moralidad depende en gran medida del hecho de que el Estado no haga acepción de personas en la aplicación de la soberanía. Y, por último, la soberanía tiene para Bodin el carácter de perpetua y absoluta. La perpetuidad está ligada al hecho mismo de la existencia del Estado: sin ella, no hay Estado. Y es absoluta, en el sentido de que no puede estar limitada por ningún poder superior a ella, ni siquiera por las leyes porque ellas mismas son el producto de la soberanía. Y esto es precisamente lo que lleva a Bodin a colocar la soberanía en la función legislativa. Ésta es una marca de soberanía, la cual llega incluso al poder, no solamente de dar la ley, sino incluso de quebrantarla: "Bajo este mismo poder de dar y quebrantar la ley se comprenden todos los otros derechos y marcas de soberanía, de modo que, para hablar con propiedad, se puede decir que no hay otra marca de soberanía más que ésta, y todos los demás derechos son comprendidos en ella."

De más está decir que todo el esfuerzo intelectual de Bodin está concentrado casi exclusivamente en la ley positiva: ése es el campo específico de la soberanía. El riesgo de arbitrariedad, sin embargo, está mitigado porque la soberanía, con ser absoluta, todavía conserva su relación con un cierto número de cadenas, tales como las leyes de Dios o de la naturaleza, por ejemplo. Pero, en esto, Bodin parece hacer una concesión a la tradición más que estar plenamente convencido de una supuesta dependencia directa del sistema jurídico positivo respecto del natural o de la ley Eterna, por ejemplo. En todo caso, el término "soberanía" es todo un 
neologismo cuya elaboración obedece a una exigencia y a una intención muy concreta, y si bien es cierto que este término acuñado por Bodin adolece de cierta ambigüedad, no es menos cierto que gracias a él éste hace su presentación oficial en la teoría política, del mismo modo que el término 'Estado' lo hizo con Maquiavelo.

Corresponde a Thomas Hobbes, de todos modos, el mérito de haber elaborado la sistematización del concepto de soberanía. Todos los términos latinos que se aproximaban al mismo son reunidos por Hobbes bajo una misma significación. Summa potestas, summum imperium, dominium, son traducidos al inglés directamente por sovereignty. Es en Hobbes donde encontramos realmente toda una teoría política, todo un sistema pretendidamente científico de pensar el Estado moderno. Pues bien, la soberanía, ya en la "Introducción" al Leviatán, es tratada como el alma misma del cuerpo político. Esta soberanía, que incluye obviamente el uso de la fuerza, está unida, según Hobbes a un cuerpo de derecho cuyas características son netamente modernas, tal como el mismo autor se encarga de recordar en sus definiciones del derecho y la ley.

Un hecho importante que debe ser subrayado en el pensamiento hobbesiano, es que en él también tenemos la introducción de la noción de "representación" asociada a la soberanía. El soberano es el "representante" de los contratantes. Pero aquellos límites de la soberanía que tornaban su tratamiento un tanto ambiguo en Bodin, en Hobbes directamente desaparecen. No hay leyes de la naturaleza ni leyes divinas, en el sentido tradicional del término, que puedan limitar el ejercicio de la soberanía. Si hay una ley fundamental, ella es la que impone a los súbditos el deber de la obediencia ${ }^{20}$.

20 "La causa final, meta o designio de los hombres (que aman naturalmente la libertad y el dominio sobre otros) al introducir entre ellos esa restricción de la vida en repúblicas es cuidar de su propia preservación y conseguir una vida más dichosa; esto es, arrancarse de esa miserable situación de guerra que se vincula necesariamente a las pasiones naturales de los hombres cuando no hay poder visible que los mantenga en el temor, o por miedo al castigo atarlos a la realización de sus pactos y a la observancia de aquellas leyes de la naturaleza expuestas [anteriormente]. Porque las leyes de la naturaleza son por sí mismas contrarias a nuestras pasiones naturales, que llevan a la parcialidad, el orgullo, la venganza y 
Es en el Leviatán donde encontramos, por primera vez, un tratamiento sistemático y explícito de dos de los caracteres del Estado, incluso tal como hoy lo conocemos: el uso de la fuerza asociado a un sistema legal soberano que no reconoce, de hecho, instancias suprajurídicas de legitimación. Que Hobbes ha sabido ver las características esenciales del

cosas semejantes cuando falta el terror hacia algún poder". “[...] El único modo de erigir un poder común capaz de defenderlos de la invasión extranjera y las injurias de unos a otros, es conferir todo su poder y fuerza a un hombre, o a una asamblea de hombres, que pueda reducir todas sus voluntades, por pluralidad de voces, a una voluntad. Lo cual equivale a elegir un hombre, o asamblea de hombres, que represente su persona; y cada uno poseer y reconocerse a sí mismo como autor de aquello que pueda hacer o provocar quien así representa a su persona, en aquellas cosas que conciernen a la paz y la seguridad común, y someter así sus voluntades, una a una, a su voluntad, y sus juicios a su juicio. Esto es más que consentimiento o concordia; es una verdadera unidad de todos ellos en una única e idéntica persona hecha por pacto de cada hombre con cada hombre, como si todo hombre debiera decir a todo hombre: autorizo y abandono el derecho a gobernarme a mí mismo, a este hombre, o a esta asamblea de hombres, con la condición de que tú abandones tu derecho a ello y autorices todas sus acciones de manera semejante. Hecho esto, la multitud así unida en una persona se llama REPÚBLICA (Commonwealth), en latín CIVITAS. Esta es la generación de ese gran LEVIATÁN [...]. Pues mediante esta autoridad, concedida por cada individuo particular en la república, administra tanto poder y fuerza que por terror a ello resulta capacitado para formar las voluntades de todos en el propósito de paz en casa y mutua ayuda contra los enemigos del exterior. Y en él consiste la esencia de la república, que (por definirla) es una persona, cuyos actos ba asumido como autora una gran multitud, por pactos mutuos de unos con otros, a los fines de que pueda usar la fuerza y los medios de todos ellos, segun considere oportuno, para su pazy defensa comuin. Y el que carga con esta persona se denomina SOBERANO y se dice que posee poder soberano; cualquier otro es SÚBDITO" (Hobbes, Leviatán, cap. XVII).

"Se dice que una repuiblica es instituida cuando una multitud de hombres se ponen efectivamente de acuerdo, y pactan cada uno con cada uno, que a un cierto bombre o asamblea de hombres se le concederá por mayoría el derecho a representar la persona de todos ellos (es decir, el derecho de ser su representante). Todos ellos, tanto quienes votaron a favor como quienes votaron en contra, autorizarán en lo sucesivo todas las acciones y juicios de ese hombre o asamblea de hombres como si fueran los suyos propios hasta el final, a fin de vivir pacíficamente entre ellos y estar protegidos frente a otros hombres" (Ibid., cap. XVIII). 
Estado, es cosa que difícilmente pueda ser discutida hoy. En efecto, ¿quién diría que una ley sancionada por el Estado no es válida, por más inmoral que pueda parecer? ¿Y quién discutiría que el uso de la fuerza es una prerrogativa exclusiva del Estado?

De todos modos, en esta casi obsesión por asegurar conceptualmente el contenido de la soberanía, Hobbes fue tal vez demasiado lejos al deducir que, dadas las características de la misma, el gobierno debe ser necesariamente monárquico y reunir en su mano la totalidad del poder. Hobbes no parece haber comprendido una sutil distinción hecha por Bodin en el sentido de que una cosa es la forma del Estado y otra la del gobierno. El Estado sí debe ser único o unitario, monárquico si se quiere, pues él monopoliza la fuerza, el derecho y la soberanía. Pero la forma de gobierno del Estado, puede ser de otra naturaleza; basta con que ella no lesione el principio de unidad del Estado.

El problema que se plantea con Hobbes es entonces el siguiente: ¿la soberanía, con los caracteres con que ha sido descrita, podría tolerar la instauración de otro tipo de gobierno, además del monárquico? Ésta es la pregunta que tácitamente se plantea John Locke, para quien el problema político ahora ya no es el de la sistematización de la soberanía. De eso ya se ha encargado magníficamente bien Hobbes. El problema ahora es más bien constitucional.

Con Locke comienza así, por primera vez, el asunto de la división o distribución del poder, cosa que para Hobbes hubiese constituido la ruina de un sistema político. Pero en realidad, esta doctrina no afectaba en absoluto a la esencia misma del Estado, que sigue conservando su soberanía absoluta.

De ninguna manera puede interpretarse que la división del poder en un "poder" ejecutivo, un "poder" legislativo y un "poder" judicial, según la célebre doctrina de Montesquieu en El espiritu de las leyes (1748-1750), libro $\mathrm{XI}$, c. 16, 17 y 18, o la división de Locke en un "poder" legislativo y otro "poder" ejecutivo-judicial-federativo implique una división de la soberanía. El soberano es siempre uno solo: el Estado. Lo que hay, en todo caso, es un fideicomiso para que uno de los poderes, en el caso de Locke el legislativo, sea el principal depositario de la soberanía. No se trata, tal como observaba 
Madison en sus reflexiones sobre Montesquieu en El Federalista, de una división de poderes, sino de una división del poder.

La novedad aportada por Locke y Montesquieu es precisamente eso, que el poder puede dividirse sin menoscabo de la soberanía del Estado, e incluso, ellos muestran de qué manera esto puede llevarse a cabo. Este aporte constituye de hecho la última expresión del Estado contemporáneo como sistema jurídico. Éste es el momento del desplazamiento de la cuestión de la soberanía, que ya no plantea prácticamente ningún problema teórico, al de la constitución. Así entonces, una vez consolidado el asunto del Estado soberano, y de manera especial habiéndose precisado el concepto de soberanía como algo intrínsecamente ligado al Estado como estructura jurídica, el gran tema de la teoría política moderna y contemporánea es el de la división del poder y la constitución. Estos son, a su vez, los grandes asuntos en juego cada vez que la "reforma del Estado" aparece como discusión política prioritaria.

El tema de la división del poder y el de la constitución hacen su aparición al mismo tiempo que se define el fin de la vida política como el disfrute de tanta libertad como sea posible articular con la de los demás para preservar la propiedad. Esto hace que el Estado, si bien es soberano, su soberanía está esencialmente orientada al servicio de la propiedad privada de los ciudadanos. Incluso la ciudadanía depende en gran medida de la propiedad. No es casual que el gran tema del Segundo tratado del gobierno civil de Locke esté en su capítulo 5, el más extenso de todos, cuyo título es, precisamente, "Sobre la propiedad". Locke es perfectamente consciente de la necesidad de argumentar a favor de la propiedad privada, particularmente acerca de ciertas formas de posesión, pues esto constituye nada más y nada menos que la principal ocupación del gobierno ${ }^{21}$.

21 "El grande y principal fin, pues, de los hombres que se unen en comunidades políticas y se ponen bajo gobierno es la preservación de sus propiedades; para lo cual, en el estado de naturaleza faltan muchas cosas" John Locke, Segundo tratado del gobierno civil, cap. 9, par. 124).: "Siendo el gran fin que persiguen los hombres al entrar en sociedad el disfrute de sus propiedades en paz y seguridad [...]" (Ibid., cap. 11, par. 134). Resulta interesante comparar este fin de la comunidad política según Locke con la perspectiva aristotélica: "Es claro, pues, que la ciudad no es una comunidad de lugar y cuyo fin sea evitar la injusticia mutua y facilitar el intercambio 
Se supone que al entrar en sociedad civil, los hombres no buscan un modo de convivencia en el cual estén peor que antes, de modo que el gobierno o el Estado, por soberanos que sean, tienen su sentido en el servicio de algo que los hombres, en estado de naturaleza, no consiguen preservar, es decir, la propiedad. De modo que en Locke ya vemos esbozarse la idea de que la soberanía absoluta, si bien de hecho reside en el Estado, el cual incluso puede darse distintas formas organizativas mediante las diversas constituciones, en el fondo, dicha soberanía no tiene otro origen último que el pueblo (el pueblo de propietarios, claro está) ${ }^{22}$. Dicho de otro modo, el análisis de Locke distingue claramente dos problemas: 1) el del ejercicio actual de la soberanía; y 2) el del origen último de la misma. Respecto de lo primero, no cabe duda de que dicho ejercicio corresponde al Estado. Y respecto de lo segundo, el pueblo es la primera fuente de donde emana la soberanía. Y si esto es así, está claro que la cabeza del Estado es un representante del pueblo o un mandatario. La soberanía del que preside el Estado es una soberanía por fideicomiso.

El camino está así definitivamente abierto para la teoría de la soberanía popular, la cual no implica de ningún modo una puesta en tela de

[...]. Hay que concluir, por tanto, que el fin de la comunidad política son las buenas acciones y no la convivencia" (Aristóteles, Politita, III, 9, 1280b 30 y ss).

22 "Aunque en una república constituida, estable sobre su propia base y actuando conforme a su propia naturaleza, esto es, actuando para la preservación de la comunidad, no puede haber sino un poder supremo que es el legislativo, al que todos los restantes están y deben estar subordinados, sin embargo, siendo el legislativo tan sólo un poder fiduciario para actuar con vistas a ciertos fines, sigue aún permaneciendo en el pueblo el supremo poder de remover o alterar el legislativo cuando descubriese que éste actúa contrariamente a la confianza depositada en él; porque hallándose todo poder confiado para el logro de un fin limitado por éste, cuando quiera que ese fin fuere manifiestamente descuidado o resistido, la confianza debe necesariamente perder su vigencia y el poder ser devuelto a las manos de quienes lo dieron, y que pueden ponerlo de nuevo donde consideraren mejor para su resguardo y seguridad. $\mathrm{Y}$ así la comunidad conserva perpetuamente el supremo poder de salvarse de los atentados y designios de quienquiera que sea, aun de los legisladores cuando quiera que fueren tan necios o tan malvados como para planear y llevar a cabo designios contra las libertades y propiedades del súbdito" (Locke, Segundo tratado del gobierno civil, cap. 13, par. 149). 
juicio de la soberanía del Estado. Ambas son perfectamente complementarias e incluso, una no puede expresarse sin la otra.

\section{Resumen}

El trabajo rastrea el origen del término Estado, la evolución de su concepto y su relación con el derecho en la Filosofía antigua y medieval, para centrarse luego en Maquiavello y en los clásicos de la Filosofía política de la modernidad. Estudia luego la aparición del concepto de soberanía especialmente en Bodino y en Hobbes, el cual, junto con el aparato legal, son los que caracterizan al Estado moderno. La exposición concluye con la introducción, a partir de Locke, de la idea de que la primera fuente de donde emana la soberanía es el pueblo. Y si esto es así, está claro que la cabeza del Estado es un representante del pueblo o un mandatario. La soberanía del que preside el Estado es una soberanía por fideicomiso. El camino está así definitivamente abierto para la teoría de la soberanía popular, la cual no implica de ningún modo una puesta en tela de juicio de la soberanía del Estado. Ambas son perfectamente complementarias e incluso, una no puede expresarse sin la otra.

Palabras clave: Filosofía política, Estado, Derecho, Soberanía.

\section{Abstract}

The paper traces the origin of the term State, the evolution of its concept and its relation with Right in ancient and medieval philosophy, and focuses then on Machiavelli and the classics of Political Philosophy of modernity. Next it turns to study the emergence of the concept of sovereignty in Bodin and Hobbes, which, together with the corpuses of law, characterize modern State. The exposition ends with the introduction, starting from Locke, of the idea that the first source from which sovereignty originates is the people. And this being so, it becomes clear that the head of the State is a representative of the people or mandatary. The sovereignty of those who preside the State is sovereignty by trust. The way is thus definitely open for the theory of popular sovereignty, which by no means implies a discussion about sovereignty of State. Both are perfectly complementary and one cannot express itself without the other.

Key words: Political Philosophy, Right, State, Sovereignty. 